\title{
Variability of plasma aprotinin concentrations in pediatric patients undergoing cardiac surgery
}

\author{
William C. Oliver, Jr, MD \\ David N. Fass, PhD \\ Gregory A. Nuttall, $\mathrm{MD}^{\mathrm{a}}$ \\ Joseph A. Dearani, $M D^{\mathrm{b}, \mathrm{c}}$ \\ Lisa M. Schrader, $\mathrm{MT}^{\mathrm{a}}$ \\ Darrell R. Schroeder, MS ${ }^{d}$ \\ Mark H. Ereth, MD \\ Francisco J. Puga, MD $D^{\mathrm{b}, \mathrm{c}}$
}

From the Department of Anesthesiology, ${ }^{\mathrm{a}}$
Division of Cardiovascular Surgery, ${ }^{\mathrm{b}}$ De-
partment of Surgery, ${ }^{\mathrm{c}}$ Division of Biostatis-
tics, ${ }^{\mathrm{e}}$ and the Department of Hematology
Research, ${ }^{\mathrm{e}}$ Mayo Foundation, Rochester,
Minn.
Funding provided by Mayo Foundation for
Medical Education and Research.
Received for publication June 24, 2003;
revisions requested Sept 26, 2003; accepted
for publication Oct 7, 2003.
Address for reprints: William C. Oliver, Jr,
MD, Department of Anesthesiology, Mayo
Clinic, 200 First St SW, Rochester, MN
55905 (E-mail: oliver.william @ mayo.edu).
J Thorac Cardiovasc Surg 2004;127:1670-7
0022-5223/ $\$ 30.00$

Copyright () 2004 by The American Association for Thoracic Surgery

doi:10.1016/j.jtcvs.2003.10.029
Objectives: Infants and children undergoing cardiopulmonary bypass for repair of congenital heart defects are at substantial risk for excessive bleeding, contributing greatly to morbidity and mortality. Aprotinin significantly reduces bleeding and transfusion requirements in adults but is of indeterminate value for pediatric patients. The aim of this study was to determine plasma aprotinin concentrations in these patients with a functional aprotinin assay.

Methods: Thirty patients less than 16 years of age scheduled for cardiac surgery with aprotinin were enrolled. Aprotinin was administered as a $25,000 \mathrm{KIU} / \mathrm{kg}$ bolus, $35,000 \mathrm{KIU} / \mathrm{kg}$ cardiopulmonary bypass prime, and $12,500 \mathrm{KIU} \cdot \mathrm{kg}^{-1} \cdot \mathrm{h}^{-1}$ continuous infusion. Blood samples for aprotinin concentrations (kallikrein-inhibiting units/milliliter) were obtained before aprotinin; 5 minutes post-bolus; 5 minutes after cardiopulmonary bypass initiation; 30 and 60 minutes on cardiopulmonary bypass; on discontinuation of aprotinin; 1 hour after aprotinin discontinuation; and 4 hours after permanent separation from cardiopulmonary bypass. For analysis, patients were grouped according to weight $(<10 \mathrm{~kg}, 10-20 \mathrm{~kg},>20 \mathrm{~kg}$ ). Differences between weight groups were assessed using an exact test for categoric variables and 1-way analysis of variance for continuous variables.

Results: Aprotinin concentrations differed significantly across weight groups. Five minutes after aprotinin bolus and initiation of cardiopulmonary bypass, there was significant correlation between weight and aprotinin concentration $(r=.57, P=$ $.003 ; r=.69, P=.001$, respectively).

Conclusion: A functional assay reveals significant variability in aprotinin concentration for pediatric patients using current weight-based aprotinin dosing. Additional investigation is necessary to determine target aprotinin concentration dosing regimens to provide better efficacy.

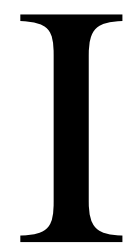

nfants and children who undergo cardiopulmonary bypass (CPB) for repair of congenital heart defects are at substantial risk for excessive bleeding and transfusion, contributing greatly to morbidity and mortality. ${ }^{1}$ Infants aged 1 year or less bleed significantly more and receive more blood products than children aged more than 1 year during the perioperative period. ${ }^{1}$ Twentyfour-hour blood loss may reach $110 \mathrm{~mL} / \mathrm{kg}$, and the median donor exposure is 6 units for infants undergoing CPB. ${ }^{2}$ The cause of the excessive bleeding and transfusion requirements is multifactorial. Hemodilution, preoperative platelet aggregation abnormalities, complex operations with prolonged duration of $\mathrm{CPB}$, 
TABLE 1. Aprotinin dosing schedules

\begin{tabular}{|c|c|c|c|c|}
\hline Author & Year & $\begin{array}{c}\text { Bolus } \\
\text { (KIU/kg) }\end{array}$ & $\begin{array}{l}\text { Pump prime } \\
\text { (KIU/kg) }\end{array}$ & $\begin{array}{l}\text { Continuous infusion } \\
\left(\mathrm{KIU} \cdot \mathbf{k g}^{-1} \cdot \mathrm{h}^{-1}\right)\end{array}$ \\
\hline Dietrich et al ${ }^{10}$ & 1993 & 15,000 & 15,000 & 0 \\
\hline Dietrich et al10 & 1993 & 30,000 & 30,000 & 0 \\
\hline Boldt et al ${ }^{5}$ & 1993 & 25,000 & 25,000 & 25,000 \\
\hline Miller et al ${ }^{9}$ & 1998 & 20,000 & 20,000 & 10,000 \\
\hline Miller et al9 & 1998 & 40,000 & 40,000 & 20,000 \\
\hline Huang et al ${ }^{11}$ & 1993 & 50,000 & $600,000 \mathrm{KIU}$ & 5000 \\
\hline Mossinger and Dietrich 12 & 1998 & 30,000 & 30,000 & 0 \\
\hline Boldt et al ${ }^{7}$ & 1993 & 20,000 & 20,000 & 20,000 \\
\hline Boldt et al7 & 1993 & 35,000 & 35,000 & 10,000 \\
\hline
\end{tabular}

KIU, Kallikrein-inhibiting unit.

severe hypothermia, and a significant inflammatory response to CPB contribute in varying degrees to create considerable hemostatic demand in these patients. ${ }^{3-5}$

Options for blood conservation are limited for infants and children. Pharmacologic blood conservation measures, such as antifibrinolytic agents, are popular because of the ease of administration and availability. Aprotinin, a serine protease inhibitor with anti-inflammatory and antifibrinolytic properties, significantly reduces bleeding and transfusion requirements in adults who undergo $\mathrm{CPB},{ }^{6}$ but it is of indeterminate value for pediatric patients. ${ }^{4,7}$ Possible explanations include study design, empiric transfusion practices, and a wide range of aprotinin dosing regimens used as indicated in Table $1 .{ }^{5,7,9-12}$ More specifically, aprotinin dosing regimens ${ }^{13}$ that do not achieve "target" aprotinin concentrations ${ }^{14}$ believed necessary to inhibit plasmin activity and fibrinolysis may be responsible for little or no hemostatic benefit in some pediatric patients. Aprotinin dosage for pediatric patients undergoing CPB has been extrapolated from dosing regimens used for adults that have not always proven efficacious. ${ }^{10,13}$ The paucity of proven aprotinin dosing regimens in adults and pediatric patients are partially related to the difficulty of determining aprotinin concentrations to validate and modify previous or current recommendations. Because severe allergic reaction, thrombosis, and renal dysfunction may occur with aprotinin, its use may be unwarranted in certain high-risk infants and children until efficacy is better established.

This study determines plasma aprotinin concentration and assesses consistency with a functional aprotinin assay in infants and children undergoing CPB who received aprotinin using a current weight-based approach.

\section{Methods}

After the protocol was approved by the institutional review board approval and informed consent was obtained from a parent or guardian, 30 patients less than 16 years of age scheduled to undergo cardiac surgery with $\mathrm{CPB}$ and receive aprotinin were enrolled. The decision to use aprotinin was determined by the surgeon and anesthesiologist caring for the patient. A patient with renal impairment associated with a serum creatinine greater than $2.5 \mathrm{mg} / \mathrm{dL}$ or allergy to aprotinin was excluded.

Anesthesia consisted of moderate-dose fentanyl (25-50 $\mu \mathrm{g} / \mathrm{kg})$ supplemented with midazolam, muscle relaxant, and volatile agent. Standard monitoring for patients undergoing cardiac surgery was used and included continuous arterial and central venous pressure monitoring. Fluid administration was minimized before the initiation of CPB. Anticoagulation was achieved with porcine heparin (Elkins-Sinn Inc, Cherry Hill, NJ) administered in an initial dose of $300 \mathrm{U} / \mathrm{kg}$ and followed by additional doses to maintain a celite activated clotting time (ACT) of more than 750 seconds (Hemochron 800, International Technidyne Co, Edison, $\mathrm{NJ})$.

The extracorporeal circuit included a membrane oxygenator (SCI-Med, Minneapolis, Minn). The circuit was primed with Plasmalyte, calcium chloride, sodium bicarbonate $8.5 \%$, mannitol $12.5 \%$, and $250 \mathrm{~mL}$ of albumin $5 \%$. If circulatory arrest or profound hypothermia was anticipated, washed packed red blood cells (PRBCs) were added to the priming volume to achieve a hematocrit (HCT) ranging from $18 \%$ to $23 \%$ on initiation of CPB. If the temperature was to remain greater than $32^{\circ} \mathrm{C}$, the $\mathrm{HCT}$ was kept at more than $25 \%$. Nonpulsatile flow during CPB was maintained at $2.2 \mathrm{~L} \cdot \min ^{-1} \cdot \mathrm{m}^{-2}$. A nasopharyngeal temperature probe was used for temperature monitoring. If circulatory arrest was used, 5 $\mathrm{mg} / \mathrm{kg}$ of thiopental, $0.5 \mathrm{~g} / \mathrm{kg}$ of mannitol $12.5 \%$, and $0.5 \mathrm{mg} / \mathrm{kg}$ of dexamethasone were given immediately before perfusion was interrupted. On rewarming, the HCT was maintained at $21 \%$ to $25 \%$. Modified ultrafiltration (MUF) was performed for 15 minutes after separation from CPB in patients weighing less than $20 \mathrm{~kg}$. Patients were enclosed with appropriate full body forced-air cover (Augustine Medical, Inc, Eden Prairie, Minn) to maintain the temperature during MUF. After MUF or separation from CPB, protamine, $0.013 \mathrm{mg} / \mathrm{U}$ of heparin, was given to neutralize heparin. Heparin was considered adequately neutralized if the ACT was within $10 \%$ of the pre-heparin baseline ACT value after protamine. Excessive blood in the CPB circuit was returned to the patient or processed as intraoperative autologous blood (IAB) with a Medtronic AT1000 (Medtronic Inc, Parker, Colo) to an HCT of 55\%. Shed mediastinal blood was not returned to the patient postoperatively. All surgical procedures were performed by one of the coauthors (F. J. P. or J. A. D.).

Allogeneic PRBCs were administered for a hemoglobin of 10 $\mathrm{g} / \mathrm{dL}$ or less after separation from CPB. Non-red blood cell- 
containing blood products were given in response to evidence of microvascular bleeding and these supporting laboratory studies: thromboelastogram, platelet count, prothrombin time, activated partial thromboplastin time, and fibrinogen concentration. In the intensive care unit (ICU), blood products were given for excessive mediastinal chest tube drainage and the previously mentioned supporting laboratory studies.

Aprotinin was infused through a dedicated central venous catheter. After a test dose, a 25,000 KIU/kg bolus, 35,000 KIU/kg prime, and $12,500 \mathrm{KIU} \cdot \mathrm{kg}^{-1} \cdot \mathrm{h}^{-1}$ continuous infusion of aprotinin was administered. The infusion was discontinued 2 hours after the patient's arrival in the ICU. Participants had blood samples for plasma aprotinin concentrations (kallikrein-inhibiting units per milliliter) obtained at these time intervals: before aprotinin (baseline); 5 minutes after the bolus; 5 minutes after initiation of $\mathrm{CPB}$; 30 and 60 minutes after initiation of CPB; on discontinuation of aprotinin; 1 hour after discontinuation of aprotinin; and 4 hours after permanent separation from CPB.

Each $800-\mu \mathrm{L}$ sample for aprotinin concentration was drawn from an arterial catheter and placed in a tube with $100 \mu \mathrm{L}$ of $3.8 \%$ sodium citrate. Samples were immediately placed on ice and separated into platelet-poor plasma and frozen at $-70^{\circ} \mathrm{C}$ until batch testing to determine the plasma aprotinin concentration. The assay is based on the ability of aprotinin to inhibit plasmin activity as the target enzyme as recently demonstrated. ${ }^{15,16}$ Plasma samples were diluted 50 -fold with $0.3 \mathrm{~mol} / \mathrm{L}$ Tris- $\mathrm{HCl}, 0.15 \mathrm{~mol} / \mathrm{L} \mathrm{NaCl}, \mathrm{pH}$ 7.3. Dilute plasma samples were incubated with $10 \mu \mathrm{L}$ of $1 \mathrm{U} / \mu \mathrm{L}$ added porcine plasmin (Sigma P-8644, St Louis, Mo) for 30 minutes. Twenty microliters of $1 \mathrm{mmol} / \mathrm{L}$ benzoyl-Phe-Val-Arg-p-nitroanilide (Sigma B-7632) were added to the sample as a plasmin substrate, and the spectrophotometric absorbance at 405 to $490 \mathrm{~nm}$ was read for 10 minutes at 30 -second intervals as an index of plasmin activity. We calculated the amount of aprotinin in the sample from a standard inhibition curve developed by adding known concentrations of aprotinin to pooled citrated normal human plasma ( $\mathrm{n}=30$, all male). Because the concentration of aprotinin added to the normal plasma in our standard inhibition curve was measured in kallikrein-inhibiting units per milliliter, we reported aprotinin concentration in kallikrein-inhibiting units per milliliter. To measure aprotinin in the patient samples, we defined the preoperative sample in the assay set as having $100 \%$ (uninhibited) plasmin activity and all other time points as having a fraction of the zero time activity. Because the baseline sample contained $0 \mathrm{KIU} / \mathrm{mL}$ aprotinin, the calculated aprotinin concentration value of this sample was adjusted to zero, and an identical adjustment was made to all the sample values of that patient assayed on that day.

The mediastinal chest tube drainage was noted at 4 and 24 hours after arrival in the ICU for each patient. Variables recorded include patient's age, gender, height, weight, preoperative medications, heart defect, surgical procedure, anesthetic medications, total heparin and protamine given, total amount of aprotinin received, duration of $\mathrm{CPB}$, aortic crossclamp and circulatory arrest, minimal temperature, total fluids and transfusion requirements for the intraoperative and initial 24-hour period in the ICU, duration of intubation, and ICU stay.

\section{Statistical Analysis}

Because of staffing difficulties involving research personnel, 2 of the 30 patients who enrolled preoperatively were not treated according to protocol; consequently, only 28 patients are included in this report. For analysis purposes, patients were grouped according to weight $(<10 \mathrm{~kg}, 10-20 \mathrm{~kg},>20 \mathrm{~kg})$. Differences between weight classifications were assessed using an exact test for categoric variables and 1-way analysis of variance for continuous variables. Pearson correlation analysis was performed to assess whether patient age or weight was significantly correlated with aprotinin concentration after the bolus or 5 minutes after initiation of CPB. In all cases, 2-sided tests were used, with $P$ values $\leq .05$ considered statistically significant.

\section{Results}

Demographic and surgical characteristics are presented in Table 2 according to weight. Expressed as milliliters per kilogram, the amount of intraoperative fluids did not differ across weight groups except for the volume of colloid administered during CPB in which heavier patients received less milliliters per kilogram $(P=.008)$. The CPB prime volume (milliliters) and the aprotinin concentration of the prime (kallikrein-inhibiting units per milliliter) increased with weight $(P=.002$ and $P<.001$, respectively). The operations are listed in Table 3. Two of the 13 patients weighing more than $20 \mathrm{~kg}$ received the half Hammersmith dose and 1 patient received the full Hammersmith dose of aprotinin. These 3 patients each weighed more than $40 \mathrm{~kg}$.

Aprotinin concentrations are displayed at 8 time intervals in Figure 1. As illustrated in Figure 1, aprotinin concentrations differed significantly across groups despite patients receiving the same weight-based dose indicated earlier. Five minutes after the bolus dose of aprotinin was administered, there was a significant positive correlation between weight and aprotinin concentration ( $r=.57, P=.003$ ) (Figure 2). Aprotinin concentration 5 minutes after the bolus dose was also correlated with patient age $(r=.44, P=.025)$. Five minutes after initiation of $\mathrm{CPB}$, there was a significant positive correlation between weight and aprotinin concentration $(r=.69, P<.001)$ (Figure 3). Similarly, there was a significant correlation between age and aprotinin concentration $(r=.59, P=.001) 5$ minutes after initiation of CPB. Perioperative transfusion requirements and blood loss are summarized in Table 4. There was some evidence $(P=$ .066) indicating that 24-hour, but not 4-hour, blood loss differs significantly according to weight. The amount of intraoperative IAB and PRBC, expressed in milliliters per kilogram, differed significantly according to weight with heavier patients receiving more $(P=.03)$ IAB and less $(P$ $<$.001) PRBC. The percentage of patients receiving fresh frozen plasma intraoperatively also differed significantly $(P$ $=.038$ ) across weight groups with a higher percentage of heavier patients receiving fresh frozen plasma. Postoperative transfusion requirements did not differ significantly 
TABLE 2. Demographics and surgical characteristics $(N=28)$

\begin{tabular}{|c|c|c|c|c|}
\hline Characteristics & $\begin{array}{c}<10 \mathrm{~kg}(\mathrm{n}=9) \\
\text { Mean } \pm \text { SD }\end{array}$ & $\begin{array}{c}10-20 \mathrm{~kg}(\mathrm{n}=6) \\
\text { Mean } \pm \text { SD }\end{array}$ & $\begin{array}{c}>20 \mathrm{~kg}(\mathrm{n}=13)^{*} \\
\text { Mean } \pm \text { SD }\end{array}$ & $P$ valuet \\
\hline Age, mo & $7.8 \pm 3.6$ & $60.2 \pm 13.7$ & $136.7 \pm 39.6$ & $<.001$ \\
\hline Gender, n (\%) & & & & .127 \\
\hline Male & $6(67)$ & $6(100)$ & $7(54)$ & \\
\hline Female & $3(33)$ & $0(0)$ & $6(46)$ & \\
\hline Weight, kg & $6.8 \pm 1.6$ & $15.5 \pm 3.4$ & $33.2 \pm 8.8$ & $<.001$ \\
\hline Body surface area, $\mathrm{m}^{2}$ & $0.4 \pm 0.1$ & $0.7 \pm 0.1$ & $1.1 \pm 0.2$ & $<.001$ \\
\hline Preoperative cyanosis, $\mathrm{n}(\%)$ & & & & .885 \\
\hline No & $5(56)$ & $4(67)$ & $6(46)$ & \\
\hline Yes & $4(44)$ & $2(33)$ & $7(54)$ & \\
\hline Anesthesia duration, $\min$ & $344 \pm 59$ & $335 \pm 68$ & $339 \pm 62$ & .964 \\
\hline Surgical time, $\min$ & $219 \pm 37$ & $247 \pm 29$ & $254 \pm 55$ & .206 \\
\hline CPB time, $\min$ & $84 \pm 23$ & $80 \pm 21$ & $86 \pm 33$ & .91 \\
\hline Crossclamp time, $\min$ & $44 \pm 27$ & $27 \pm 19$ & $42 \pm 34$ & .553 \\
\hline \multicolumn{5}{|l|}{ CPB fluids } \\
\hline Crystalloid, mL/kg & $135.6 \pm 97.1$ & $94.6 \pm 48.7$ & $94.4 \pm 60.1$ & .387 \\
\hline Colloid, $\mathrm{mL} / \mathrm{kg}$ & $26.4 \pm 20.7$ & $12.0 \pm 9.9$ & $6.9 \pm 6.3$ & .008 \\
\hline \multirow{2}{*}{\multicolumn{5}{|c|}{$\begin{array}{l}\text { Intraoperative fluids } \\
\text { (excluding CPB) }\end{array}$}} \\
\hline & & & & \\
\hline Crystalloid, mL/kg & $28.2 \pm 14.3$ & $35.9 \pm 17.1$ & $29.4 \pm 16.1$ & 631 \\
\hline Colloid, $\mathrm{mL} / \mathrm{kg}$ & $9.2 \pm 12.0$ & $11.3 \pm 14.4$ & $5.8 \pm 7.9$ & .578 \\
\hline Total, $\mathrm{mL} / \mathrm{kg}$ & $37.3 \pm 18.4$ & $47.2 \pm 26.6$ & $35.2 \pm 22.1$ & .553 \\
\hline \multicolumn{5}{|l|}{ CPB prime } \\
\hline Total volume, $\mathrm{mL}$ & $905 \pm 155$ & $1216 \pm 550$ & $1605 \pm 457$ & .002 \\
\hline Aprotinin, KIU/mL & $270.1 \pm 70.3$ & $517.4 \pm 218.2$ & $716.6 \pm 190.9$ & $<.001$ \\
\hline
\end{tabular}

$C P B$, Cardiopulmonary bypass.

*Two patients $(46.7$ and $41.8 \mathrm{~kg}$ ) received a half dose of aprotinin and 1 patient $(44.2 \mathrm{~kg})$ received a full dose of aprotinin rather than the pediatric dosing schedule.

$\dagger P$ values from Fisher's exact test for categoric variables and 1-way analysis of variance for continuous variables.

across weight groups. However, similar to the intraoperative period, for the total perioperative period (intraoperative + 24 hours postoperative) the amount of IAB and PRBC transfused and the percentage of patients exposed to fresh frozen plasma differed significantly across weight groups (Table 4). One patient, weighing more than $20 \mathrm{~kg}$, required mediastinal exploration for bleeding. There was no early mortality.

\section{Discussion}

Aprotinin has been shown repeatedly to significantly reduce bleeding and transfusion requirements in adults undergoing CPB with a fixed-dose regimen since $1987 .{ }^{6,14}$ In contrast, similar results in children undergoing CPB with aprotinin have been indeterminate in neonates and infants even with weight-based dosing regimens. ${ }^{7,8,13,17}$ Pediatric and adult studies have rarely determined aprotinin concentrations to validate or modify existing dosing regimens. Similar to Dietrich and colleagues' study, ${ }^{10}$ this study defines plasma aprotinin concentrations in infants undergoing CPB but it also includes children aged less than 16 years. The study indicates that the failure of current pediatric aprotinin dosing regimens to achieve target aprotinin concentrations is partially a result of the difference in the volume of distri- bution of aprotinin in infants compared with adults. Furthermore, clearance of aprotinin and weight-based priming dose are also important factors in the variability of aprotinin concentrations with current dosing regimens.

Through application of our functional assay in patients less than 16 years of age undergoing cardiac surgery with $\mathrm{CPB}$, large variations in aprotinin concentrations were identified at the 8 time periods examined with the current investigation. Previously, Dietrich and colleagues ${ }^{10}$ characterized plasma aprotinin concentrations only in infants with congenital heart disease undergoing CPB. Forty infants weighing less than $10 \mathrm{~kg}$ received either $30,000 \mathrm{KIU} / \mathrm{kg}$ or $60,000 \mathrm{KIU} / \mathrm{kg}$ of aprotinin intraoperatively as a bolus and pump prime without incorporating a continuous infusion. With similar sampling times in our investigation, peak aprotinin concentrations were only $99 \pm 25 \mathrm{KIU} / \mathrm{mL}$ for the infants receiving the higher dose of aprotinin. These aprotinin concentrations are lower than the aprotinin concentrations found in patients weighing less than $10 \mathrm{~kg}$ in our study. Not surprisingly, the total amount of aprotinin and dosage of aprotinin in our infants weighing less than $10 \mathrm{~kg}$ $(948,796 \pm 266,108 \mathrm{KIU})$ is considerably higher than that found by Dietrich and colleagues ${ }^{10}(180,000 \pm 81,000$ KIU). The significance of aprotinin concentrations centers 
TABLE 3. Operative procedures*

\begin{tabular}{|c|c|c|c|}
\hline & $\begin{array}{l}<10 \text { kg } \\
(n=9)\end{array}$ & $\begin{array}{c}10-20 \mathrm{~kg} \\
(\mathrm{n}=6)\end{array}$ & $\begin{array}{r}>20 \mathrm{~kg} \\
(\mathrm{n}=13)\end{array}$ \\
\hline Aortic valve replacement & & & 1 \\
\hline $\begin{array}{l}\text { Bidirectional cavopulmonary } \\
\text { anastomosis }\end{array}$ & 1 & & 1 \\
\hline Central shunt & & & 1 \\
\hline Complete AV canal repair & 3 & & 1 \\
\hline $\begin{array}{l}\text { Complete repair of } \mathrm{AV} \text { canal } \\
\text { with TOF }\end{array}$ & 1 & 1 & \\
\hline Fontan conversion & & & 1 \\
\hline Modified Fontan & & 2 & 3 \\
\hline Pulmonary valve replacement & & & 3 \\
\hline $\begin{array}{l}\text { Replacement ascending } \\
\text { aorta }\end{array}$ & & & 1 \\
\hline $\begin{array}{l}\text { Resection of subaortic } \\
\text { stenosis }\end{array}$ & & 1 & \\
\hline $\begin{array}{l}\text { RV to } P A \text { conduit } \\
\text { replacement }\end{array}$ & & 2 & \\
\hline $\begin{array}{l}\text { RV outflow tract } \\
\text { reconstruction }\end{array}$ & & & 3 \\
\hline Tricuspid valve repair & & & 1 \\
\hline Tricuspid valve replacement & & & 1 \\
\hline TAPVC complete repair & & 1 & \\
\hline $\begin{array}{l}\text { TOF with absent pulmonary } \\
\text { valve repair }\end{array}$ & 1 & & \\
\hline TOF repair & 2 & & \\
\hline VSD closure & 1 & & 1 \\
\hline
\end{tabular}

$A V$, Atrioventricular; $P A$, pulmonary artery; $R V$, right ventricular; $T O F$, tetralogy of Fallot; VSD, ventricular septal defect; TAPVC, total anomalous pulmonary venous connection.

${ }^{*}$ Some patients received more than 1 procedure per operation.

on the fact that in vitro plasma concentrations of aprotinin have been related to antifibrinolytic and anti-inflammatory activity at concentrations of $125 \mathrm{KIU} / \mathrm{mL}$ and $200 \mathrm{KIU} / \mathrm{mL}$, respectively. ${ }^{14}$ Although others have reported the antifibrinolytic activity of aprotinin to occur at a concentration as low as $50 \mathrm{KIU} / \mathrm{mL},{ }^{18}$ it is certain that the anti-inflammatory activity associated with kallikrein inhibition occurs at a much higher plasma aprotinin concentration than antifibrinolysis. Notably, these "target" aprotinin concentrations are not consistently achieved with current aprotinin weightbased dosing regimens for infants and children.

Highly variable aprotinin concentrations have also recently been reported in adults receiving aprotinin for cardiac surgery requiring CPB. ${ }^{15,16}$ Beath and colleagues ${ }^{15}$ attributed fluctuations in aprotinin concentrations in their investigation in large part to the fixed amount of aprotinin administered in accordance with the popularized "Hammersmith" dose regimen. ${ }^{14}$ Consequently, the degree of variability in aprotinin concentration despite weightbased dosing in our pediatric subjects suggests other factors to explain it. Foremost, hemodilution is recognized as more pronounced in infants and smaller children than in adults because priming volumes may exceed the infant's blood

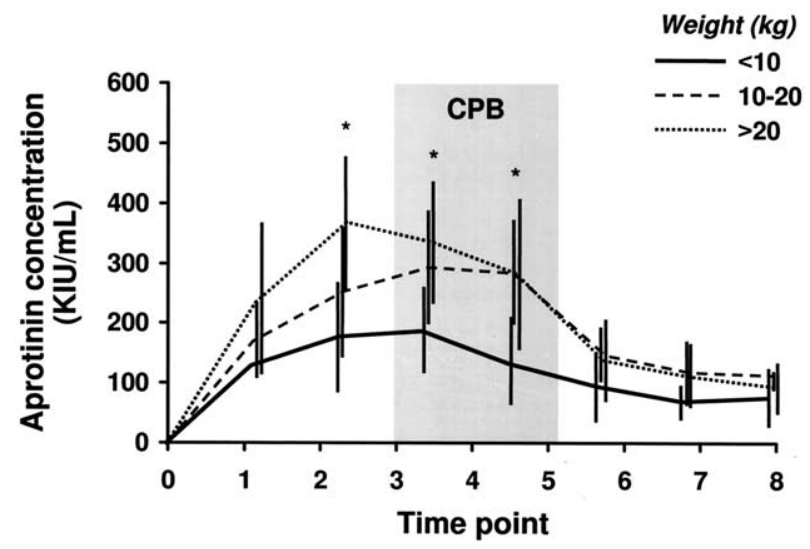

Figure 1. Plasma aprotinin concentrations determined for each patient at the following time intervals: (1) baseline (before aprotinin administration); (2) 5 minutes after aprotinin bolus; (3) 5 minutes after initiation of CPB; (4) 30 minutes during CPB; (5) 60 minutes during CPB; (6) discontinuation of aprotinin infusion; (7) 1 hour after aprotinin infusion was discontinued; and (8) 4 hours after permanent separation from CPB. Aprotinin was administered as a $25,000 \mathrm{KIU} / \mathrm{kg}$ bolus, $35,000 \mathrm{KIU} / \mathrm{kg}$ priming component, and $12,500 \mathrm{KIU} \cdot \mathrm{kg}^{-1} \cdot \mathrm{h}^{-1}$ continuous infusion. One patient received full dose $(280 \mathrm{mg}$ bolus, $280 \mathrm{mg}$ prime, and $70 \mathrm{mg} / \mathrm{h}$ continuous infusion), and 2 patients received half dose (140 $\mathrm{mg}$ bolus, $140 \mathrm{mg}$ prime, and $35 \mathrm{mg} / \mathrm{h}$ continuous infusion). All of these patients weighed more than $\mathbf{4 0} \mathbf{~ k g}$. *Significant difference across weight groups $(P<.05,1-$ way analysis of variance). $C P B$, Cardiopulmonary bypass; $K I U$, kallikrein-inhibiting unit.

volume by as much as $400 \%$. Dietrich and colleagues ${ }^{10}$ also ascribed lower plasma aprotinin levels to the degree of hemodilution associated with infants undergoing CPB. In addition, the pharmacokinetics of infants and children vary greatly from adults because of greater volume of distributions and liver or renal immaturity. ${ }^{19}$ These 2 factors, hemodilution and pediatric pharmacokinetics, need to be considered in the formulation of an aprotinin dosing regimen for infants and children who require cardiac surgery and CPB.

In contrast with experiences of older children receiving aprotinin, ${ }^{8}$ studies in neonates and infants have been at variance regarding transfusion requirements and blood loss. ${ }^{7}$ Our study reveals a strong positive relationship between weight and aprotinin concentration before (Figure 2) and during (Figure 3) CPB. Accordingly, infants may not attain aprotinin concentrations believed to confer anti-inflammatory or even antifibrinolytic activity, accounting for some of the discrepancy between older and younger patients regarding benefit. However, no investigation has proven that a specific aprotinin concentration is associated with reduced transfusion and bleeding in patients undergoing $\mathrm{CPB}$. Dietrich and colleagues ${ }^{10}$ correlated aprotinin concentration with fibrin monomer levels, revealing lower fibrin 


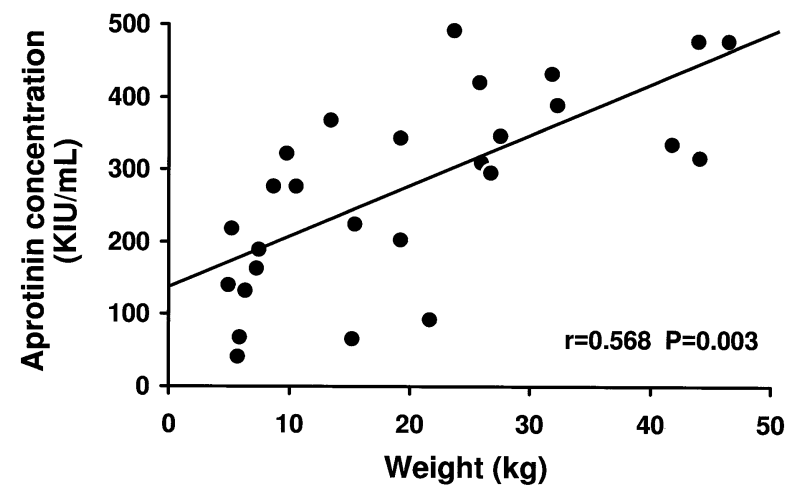

Figure 2. Plasma aprotinin concentrations 5 minutes after the bolus of aprotinin according to weight.

generation associated with a higher aprotinin concentration that was also associated with significantly lower 6-hour blood loss compared with patients who received lower dose aprotinin. This indicates improved results with achievement of higher blood concentrations of aprotinin.

Although our study was not powered to assess transfusion and blood loss between infants and children as a function of weight, overall there was a tendency for the infants weighing less than $10 \mathrm{~kg}$ to bleed more postoperatively. It has been demonstrated that infants weighing less than $8 \mathrm{~kg}$ and aged less than 1 month are more likely to bleed excessively than older and heavier children. ${ }^{1,20} \mathrm{Al}-$ though red blood cell loss may be partially responsible for PRBC transfusions, significant differences in intraoperative allogeneic PRBCs identified in the study are likely the result of greater hemodilution that accompanies infants undergoing $\mathrm{CPB}$. Beyond requiring more intraoperative PRBCs, patients weighing less than $10 \mathrm{~kg}$ experienced greater 24hour mediastinal chest tube drainage than older patients in accordance with the results of Miller and colleagues ${ }^{20}$ and Williams and colleagues. ${ }^{1}$ Our study is unable to reach any definitive conclusions about the relationship between blood loss and transfusion and the marked variability of plasma aprotinin concentrations in this pediatric population, although it needs to be answered to fully assess future aprotinin dosing regimens.

Any attempt to develop recommendations for aprotinin regarding infants and children undergoing CPB should include attainment of "target" aprotinin concentrations for inhibition of fibrinolysis. Because of the marked systemic inflammatory response that occurs as a result of CPB in neonates and infants, ${ }^{21}$ inhibition of the inflammatory response and fibrinolysis may be crucial. Our data indicate that pediatric patients require dosing schedules that account for their weights in relation to the size of the CPB circuits and their pharmacokinetic differences. If the priming dose of aprotinin is administered on the basis of a subject's

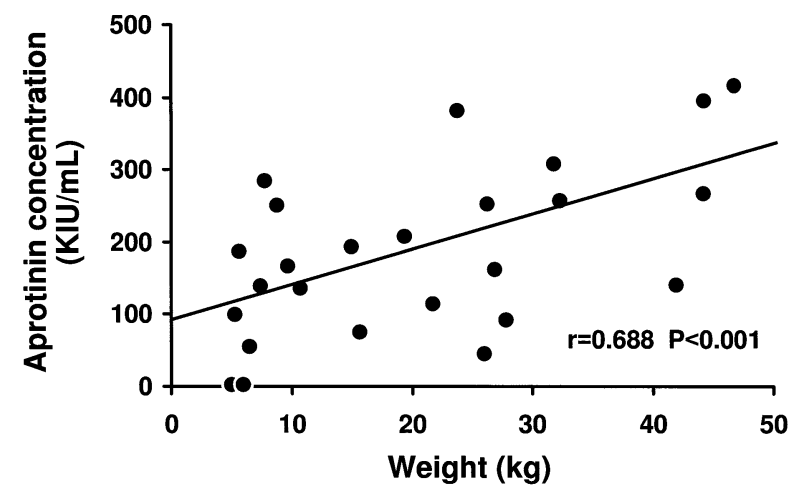

Figure 3. Plasma aprotinin concentrations 5 minutes after the initiation of CPB according to weight.

weight alone, as is currently the practice, aprotinin concentrations will be significantly less than concentrations believed necessary to inhibit fibrinolysis and the inflammatory response. As a result, we are developing a dosing regimen for aprotinin that compensates for the apparent discrepancy between the pediatric patient's blood volume and the priming volume used for CPB to achieve aprotinin concentrations in the range of 200 to $250 \mathrm{KIU} / \mathrm{mL}$.

This study is limited in that we have determined plasma aprotinin concentrations in a very heterogeneous patient population with considerable pharmacokinetic variability that may have distorted the relationship of aprotinin concentrations and certain weight relationships. In addition, the number of patients weighing less than $10 \mathrm{~kg}$ was inadequate to develop strong conclusions about this population. Without statistical power to assess differences in blood loss or transfusion requirements in relation to aprotinin concentrations, we are unable to comment about the importance of attaining "target" aprotinin concentrations in this area. Finally, in contrast with our study, Dietrich and colleagues ${ }^{10}$ used a competitive enzyme-linked immunosorbent assay (ELISA) as described by Muller-Esterl and colleagues ${ }^{22}$ rather than a functional assay for determination of plasma aprotinin concentration. The validity of our functional assay has been established in comparison with the ELISA-based aprotinin concentrations with excellent correlation $\left(\mathrm{r}^{2}=\right.$ $0.94),{ }^{15}$ but we did not perform any direct comparisons with the ELISA in this study to further validate the correlation of this functional assay. Recently, Cardigan and colleagues ${ }^{23}$ compared a functional aprotinin assay with ELISA in patients undergoing cardiac surgery. The correlation between the 2 methods of measurement were excellent $(r=.87)$, but the functional assay was significantly higher than the ELISA $(234 \pm 104 \mathrm{KIU} / \mathrm{mL}$ vs $155 \pm 88 \mathrm{KIU} / \mathrm{mL}$, respectively, $P=.0001)$. This indicates that the results obtained with the different assays are not interchangeable. The benefit of one assay compared with another cannot be deter- 
TABLE 4. Outcomes: Blood loss, transfusions, and complications $(\mathbf{N}=\mathbf{2 8})$

\begin{tabular}{|c|c|c|c|c|c|c|c|}
\hline \multirow[b]{2}{*}{ Characteristics } & \multicolumn{2}{|c|}{$<10 \mathrm{~kg}(\mathrm{n}=9)$} & \multicolumn{2}{|c|}{$10-20 \mathrm{~kg}(\mathrm{n}=6)$} & \multicolumn{2}{|c|}{$>20 \mathrm{~kg}(\mathrm{n}=13)$} & \multirow[b]{2}{*}{$P$ value } \\
\hline & Median & Mean \pm SD & Median & Mean \pm SD & Median & Mean \pm SD & \\
\hline \multicolumn{8}{|l|}{ ICU blood loss } \\
\hline 4-h MCTD (mL/kg) & 5.3 & $5.3 \pm 1.8$ & 6.2 & $7.9 \pm 6.2$ & 4.4 & $5.1 \pm 1.9$ & .203 \\
\hline 24-h MCTD (mL/kg) & 20.1 & $22.8 \pm 9.2$ & 16.6 & $22.3 \pm 13.6$ & 11.9 & $14.3 \pm 5.7$ & .066 \\
\hline \multicolumn{8}{|l|}{ Transfusions } \\
\hline $\begin{array}{l}\text { Intraoperative IAB }(\mathrm{mL} / \mathrm{kg}) \\
\text { Allogenic } \mathrm{RBC}\end{array}$ & 8.4 & $7.1 \pm 7.3$ & 12.4 & $12.1 \pm 4.2$ & 14.5 & $16.1 \pm 8.3$ & .03 \\
\hline $\begin{array}{l}\mathrm{mL} / \mathrm{kg} \\
\text { Transfused, \% }\end{array}$ & 72.9 & $\begin{array}{l}76.1 \pm 33.6 \\
100\end{array}$ & 24.6 & $\begin{array}{l}32.1 \pm 17.7 \\
100\end{array}$ & 11.1 & $\begin{array}{l}12.0 \pm 11.7 \\
67\end{array}$ & $\begin{array}{c}<.001 \\
.06\end{array}$ \\
\hline \multicolumn{8}{|l|}{ Fresh frozen plasma } \\
\hline $\begin{array}{l}\mathrm{mL} / \mathrm{kg} \\
\text { Transfused, } \%\end{array}$ & 0 & $\begin{array}{l}16.9 \pm 29.1 \\
33\end{array}$ & 8 & $\begin{array}{l}11.6 \pm 13.6 \\
50\end{array}$ & 8.9 & $\begin{array}{l}10.1 \pm 8.1 \\
85\end{array}$ & $\begin{array}{l}.693 \\
.038\end{array}$ \\
\hline \multicolumn{8}{|l|}{ Platelets } \\
\hline $\mathrm{mL} / \mathrm{kg}$ & 0 & $9.3 \pm 27.8$ & 0 & $5.2 \pm 8.5$ & 0 & $4.6 \pm 5.6$ & .8 \\
\hline Transfused, \% & & 11 & & 33 & & 46 & .321 \\
\hline \multicolumn{8}{|l|}{ Postoperative } \\
\hline $\begin{array}{r}\text { IAB }(\mathrm{mL} / \mathrm{kg}) \\
\text { Allogenic } \mathrm{RBC}\end{array}$ & 0 & $0.4 \pm 1.1$ & 0 & $3.2 \pm 5.4$ & 0 & $1.7 \pm 3.0$ & .267 \\
\hline $\begin{array}{l}\mathrm{mL} / \mathrm{kg} \\
\text { Transfused, \% }\end{array}$ & 0 & $\begin{array}{l}3.1 \pm 7.8 \\
22\end{array}$ & 0 & $\frac{1.9 \pm 4.5}{17}$ & 0 & $\begin{array}{l}4.5 \pm 5.3 \\
46\end{array}$ & $\begin{array}{l}.652 \\
.374\end{array}$ \\
\hline \multicolumn{8}{|l|}{ Fresh frozen plasma } \\
\hline $\begin{array}{l}\mathrm{mL} / \mathrm{kg} \\
\text { Transfused, } \%\end{array}$ & 0 & $\begin{array}{l}0 \\
0\end{array}$ & 0 & $\begin{array}{l}2.8 \pm 6.8 \\
17\end{array}$ & 0 & $\begin{array}{l}1.5 \pm 3.1 \\
23\end{array}$ & $\begin{array}{l}.365 \\
.309\end{array}$ \\
\hline \multicolumn{8}{|l|}{ Platelets } \\
\hline $\mathrm{mL} / \mathrm{kg}$ & 0 & 0 & 0 & $1.1 \pm 2.6$ & 0 & $1.3 \pm 3.1$ & .491 \\
\hline Transfused, \% & & 0 & & 17 & & 15 & .571 \\
\hline \multicolumn{8}{|l|}{ Total } \\
\hline $\begin{array}{r}I A B(\mathrm{~mL} / \mathrm{kg}) \\
\text { Allogenic } \mathrm{RBC}\end{array}$ & 8.4 & $7.4 \pm 7.5$ & 16.7 & $15.4 \pm 4.5$ & 16.1 & $17.8 \pm 9.6$ & .022 \\
\hline $\begin{array}{l}\mathrm{mL} / \mathrm{kg} \\
\text { Transfused, \% }\end{array}$ & 72.9 & $\begin{array}{l}79.1 \pm 32.3 \\
100\end{array}$ & 29.9 & $\begin{array}{l}33.9 \pm 17.5 \\
100\end{array}$ & 13.2 & $\begin{array}{l}16.2 \pm 11.8 \\
83\end{array}$ & $\begin{array}{r}<.001 \\
.487\end{array}$ \\
\hline \multicolumn{8}{|l|}{ Fresh frozen plasma } \\
\hline $\begin{array}{l}\mathrm{mL} / \mathrm{kg} \\
\text { Transfused, \% }\end{array}$ & 0 & $\begin{array}{l}16.9 \pm 29.1 \\
33\end{array}$ & 16.4 & $\begin{array}{l}14.4 \pm 12.4 \\
67\end{array}$ & 9.2 & $\begin{array}{l}11.6 \pm 8.6 \\
85\end{array}$ & $\begin{array}{l}.805 \\
.047\end{array}$ \\
\hline \multicolumn{8}{|l|}{$\begin{array}{l}\text { Platelets } \\
\text { Pat }\end{array}$} \\
\hline $\mathrm{mL} / \mathrm{kg}$ & 0 & $9.3 \pm 27.8$ & 3.2 & $6.3 \pm 8.1$ & 5.8 & $5.8 \pm 6.2$ & .888 \\
\hline \multicolumn{8}{|l|}{ Complications } \\
\hline Surgical reoperation within $24 \mathrm{~h}$ & & $0(0)$ & & $0(0)$ & & $1(8)$ & 1 \\
\hline
\end{tabular}

$I C U$, Intensive care unit; $M C T D$, mediastinal chest tube drainage; $R B C$, red blood cell; $I A B$, intraoperative autologous blood.

${ }^{*} P$ values from Fisher's exact test for categoric variables and 1-way analysis of variance for continuous variables.

mined yet with regard to determining the most effective dosing regimen for aprotinin use in cardiac surgery and congenital heart repair.

\section{Conclusion}

A functional assay for aprotinin concentration reveals significant variability in pediatric patients on the basis of weight classifications despite current weight-based aprotinin dosing for CPB. The neonate and infant seem to be at greater risk for subtherapeutic levels of aprotinin than the older and heavier pediatric patient undergoing CPB primarily because of priming volumes in excess of blood volume and altered pharmacokinetics. Dosing regimens that achieve "target" aprotinin concentrations for pediatric patients of all weight groups need to be developed and evaluated for impact on perioperative transfusion requirements and blood loss. As a result, the role of aprotinin in blood conservation strategy for pediatric patients undergoing cardiac surgery and CPB will be better defined.

The authors thank Debra Kirtz for her secretarial assistance, Suzanna Stevens for help with the data analysis, and study assistants Laurie Olsen and Devin Kutzscher for their contribution to the study.

\section{References}

1. Williams GD, Bratton SL, Ramamoorthy C. Factors associated with blood loss and blood product transfusions: a multivariate analysis in children after open-heart surgery. Anesth Analg. 1999;89:57-64. 
2. Manno CS, Hedberg KW, Kim HC, Bunin GR, Nicolson S, Jobes D, et al. Comparison of the hemostatic effects of fresh whole blood, stored whole blood, and components after open heart surgery in children. Blood. 1991;77:930-6.

3. Kern FH, Morana NJ, Sears JJ, Hickey PR. Coagulation defects in neonates during cardiopulmonary bypass. Ann Thorac Surg. 1992;54: 541-6.

4. Guay J, Rivard GE. Mediastinal bleeding after cardiopulmonary bypass in pediatric patients. Ann Thorac Surg. 1996;62:1955-60.

5. Boldt J, Knothe C, Zickmann B, Wege N, Dapper F, Hempelmann G. Aprotinin in pediatric cardiac operations: platelet function, blood loss, and use of homologous blood. Ann Thorac Surg. 1993;55:1460-6.

6. Fremes SE, Wong BI, Lee E, Mai R, Christakis GT, McLean RF, et al. Metaanalysis of prophylactic drug treatment in the prevention of postoperative bleeding. Ann Thorac Surg. 1994;58:1580-8.

7. Boldt J, Knothe C, Zickmann B, Wege N, Dapper F, Hempelmann G. Comparison of two aprotinin dosage regimens in pediatric patients having cardiac operations: influence on platelet function and blood loss. J Thorac Cardiovasc Surg. 1993;105:705-11.

8. Penkoske PA, Entwistle LM, Marchak BE, Seal RF, Gibb W. Aprotinin in children undergoing repair of congenital heart defects. Ann Thorac Surg. 1995;60:S529-32.

9. Miller BE, Tosone SR, Tam VK, Kanter KR, Guzzetta NA, Bailey JM, et al. Hematologic and economic impact of aprotinin in reoperative pediatric cardiac operations. Ann Thorac Surg. 1998;66:535-41.

10. Dietrich W, Mossinger $H$, Spannagl M, Jochum M, Wendt $P$, Barankay A, et al. Hemostatic activation during cardiopulmonary bypass with different aprotinin dosages in pediatric patients having cardiac operations. J Thorac Cardiovasc Surg. 1993;105:712-20.

11. Huang H, Ding W, Su Z, Zhang W. Mechanism of the preserving effect of aprotinin on platelet function and its use in cardiac surgery. J Thorac Cardiovasc Surg. 1993;106:11-8.

12. Mossinger H, Dietrich W. Activation of hemostasis during cardiopul- monary bypass and pediatric aprotinin dosage. Ann Thorac Surg. 1998;65:S45-51.

13. D'Errico CC, Munro HM, Bove EL. Pro: the routine use of aprotinin during pediatric cardiac surgery is a benefit. J Cardiothorac Vasc Anesth. 1999;13:782-4.

14. Royston D. High-dose aprotinin therapy: a review of the first five years' experience. J Cardiothorac Vasc Anesth. 1992;6:76-100.

15. Beath SM, Nuttall GA, Fass DN, Oliver WC Jr, Ereth MH, Oyen LJ. Plasma aprotinin concentrations during cardiac surgery: full-versus half-dose regimens. Anesth Analg. 2000;91:257-64.

16. Nuttall GA, Fass DN, Oyen LJ, Oliver WC Jr, Ereth MH. A study of a weight-adjusted aprotinin dosing schedule during cardiac surgery. Anesth Analg. 2002;94:283-9.

17. D'Errico CC, Shayevitz JR, Martindale SJ, Mosca RS, Bove EL. The efficacy and cost of aprotinin in children undergoing reoperative open heart surgery. Anesth Analg. 1996;83:1193-9.

18. Verstraete M. Clinical application of inhibitors of fibrinolysis. Drugs. 1985;29:236-61.

19. Evans WE, Schentag JJ, Jusko WJ, editors. Applied pharmacokinetics: principles of therapeutic drug monitoring. 3rd ed. Vancouver (WA): Applied Therapeutics Inc; 1992.

20. Miller BE, Mochizuki T, Levy JH, Bailey JM, Tosone SR, Tam VK, et al. Predicting and treating coagulopathies after cardiopulmonary bypass in children. Anesth Analg. 1997;85:1196-202.

21. Davies LK. Cardiopulmonary bypass in infants and children: how is it different? J Cardiothorac Vasc Anesth. 1999;13:330-45.

22. Muller-Esterl W, Oettl A, Truscheit E, Fritz H. Monitoring of aprotinin plasma levels by an enzyme-linked immunosorbent assay (ELISA). Fresenius Z Anal Chem. 1984;317:718-22.

23. Cardigan RA, Mackie IJ, Gippner-Steppert C, Jochum M, Royston D, Gallimore MJ. Determination of plasma aprotinin levels by functional and immunologic assays. Blood Coagul Fibrinolysis. 2001;12:37-42.

\section{Availability of Journal back issues}

As a service to our subscribers, copies of back issues of The Journal of Thoracic and Cardiovascular Surgery for the preceding 5 years are maintained and are available for purchase from Elsevier Inc. until inventory is depleted. Please write to Elsevier Inc., Subscription Customer Service, 6277 Sea Harbor Dr, Orlando, FL 32877, or call $800-654-2452$ or $407-345-4000$ for information on availability of particular issues and prices. 